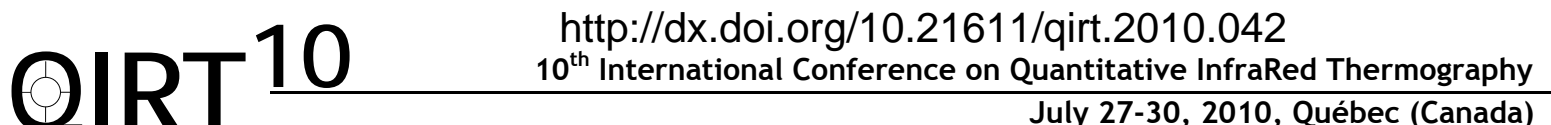 \\ July 27-30, 2010, Québec (Canada)
}

\section{Thermal analysis of Fluid flow in microchannels. Application to nanofluids}

\author{
by 0. Fudym* \&**, F. Sepúlveda*, H. Massard*
}

\begin{abstract}
* Ecole des Mines Albi, Centre RAPSODEE, Campus Jarlard, F-81013 Albi, France
Phone : (33) 563493024 -Fax : (33) 563493243 - fudym@mines-albi.fr

**TREFLE-ENSAM, UMR 8508 CNRS, Talence, France
\end{abstract}

\begin{abstract}
Nanofluids are suspensions consisting of solid nanoparticles with sizes generally less than 100nm. Nanofluid technology becomes a new challenge for the heat transfer fluid since it has been reported that the thermal conductivity of nanofluid is anomalously enhanced at a very low volume fraction(Choi,2001). The effect of particle inclusions on the effective thermal conductivity of liquid has attracted a great interest experimentally and theoretically. Very recent papers(Yu,2008), (Murshed,2008) provide a detailed literature review of nanofluids including synthesis, potential applications, experimental and analytical analysis of effective thermal conductivity, effective thermal diffusivity and convective heat transfer. Unfortunately, many works devoted to thermal conductivity measurements yield highly dispersed and non concordant results. As the main application which is envisioned for nanofluids is to use them for its heat transport capacity in heat exchangers, we propose in this work to study and evaluate directly the performance of nanofluids in microchannels instead of estimating the thermal conductivity. Both pure water and a water based Al2O3 nanofluid were flowed into a Low Temperature Cofired Ceramic micro heat exchanger (LTCC).

The experimental setup is presented in figure 1: the fluid is infused into the microchannel with a syringe pump. A laser diode is used as to promote a local spot of photothermal heat excitation. The resulting thermal field at the upper wall of the microchannel is recorded with a TITANIUM InSb $640 \times 512$ infrared camera.

As the microchannel is inserted in the microreactor and not at the wall, a 3D model is made necessary. Hopefully, a simpler 2D model can be implemented within two different approaches: the first one considers the convection-diffusion equations and is reduced through a Taylor dispersion approach. The second possibility is to consider the microchannel as a line heat source, then an analytical solution is implemented.
\end{abstract}

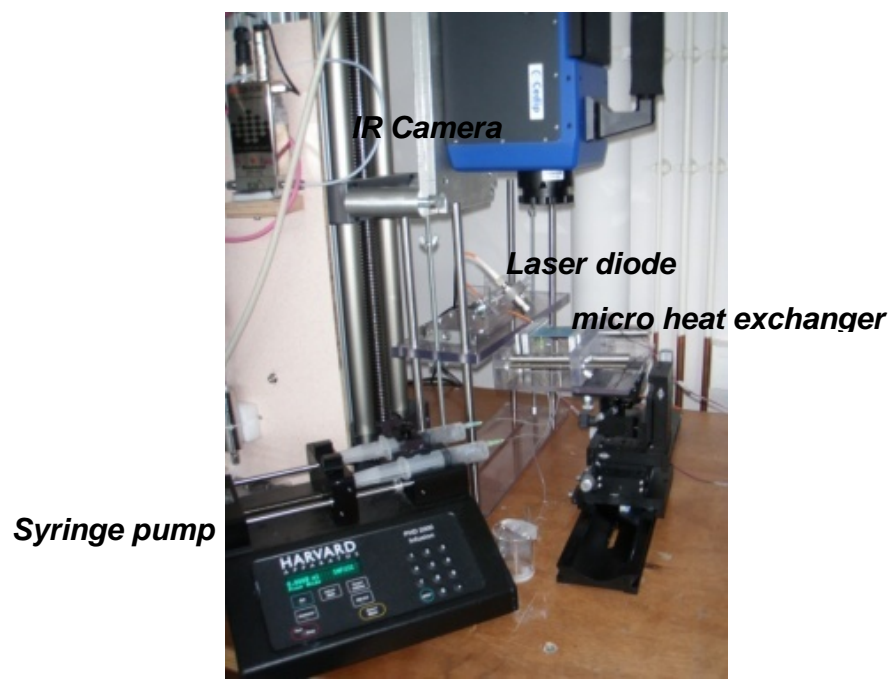

Fig. 1. Experimental Setup: IR camera, Laser diode, microchannel (LTCC micro heat exchanger), and syringe pump

In figure 2 are shown the thermal fields obtained for a fluid flow of $15 \mathrm{ml} / \mathrm{hr}$ both for pure water and the Al203 nanofluid with a $4 \%$ volume fraction of nanoparticles content. It can be noticed that the thermal field due to the laser diode spot is modified by the fluid flow. This deformation obviously contains the information relative to the velocity and the heat released by the fluid. 

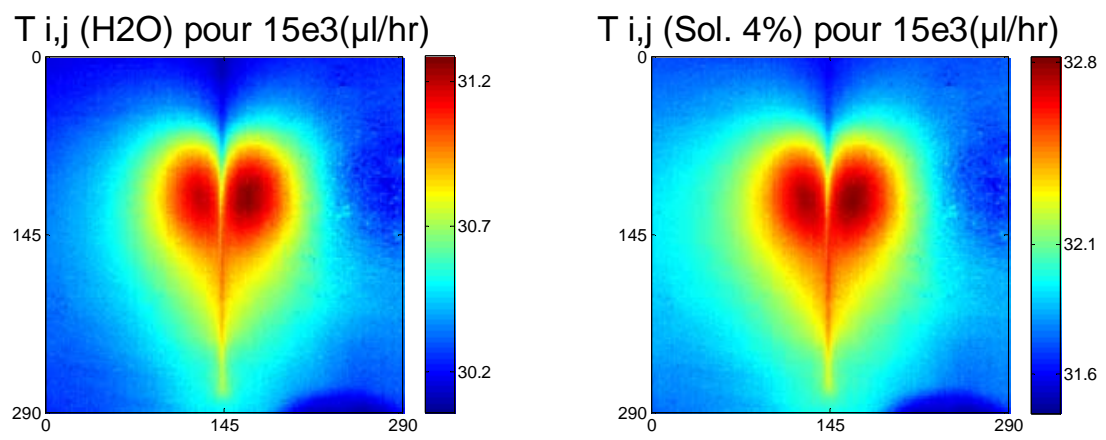

Fig. 2.Thermal field in the upper wall of te microreactor for a fluid flow rate of $15 \mathrm{ml} / \mathrm{hr}$ (a) pure water (b) nanofluid

The experimental fields are processed in order to retrieve the heat flux transported by the fluid flow. A relative thermal diffusivity is then estimated, sowing an important increase for low volumetric fluid flow rates.

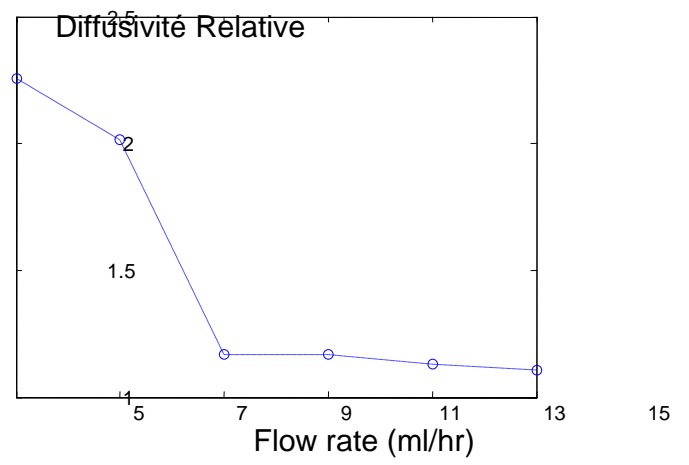

Fig. 3. Relative thermal diffusivity between nanofluid and pure water

\section{REFERENCES}

[1] Tavman I.,Turgut A., Chirtoc M., Hadjov K., Fudym O., Tavman S., Experimental study on thermal conductivity and viscosity of water based nanofluids, Int. Symp. On Convective Heat and Mass Transfer in Sustainable Energy, April 26 - May 1, 2009, Tunisia

[2] Chirtoc M, Antoniow J.S., Henry J.F., Dole P., Pelzl J., 1w, 2w, 3w scanning thermal microscopy (SThM) and combinations with thermographic, radiometric, pyroelectric and thermoelastic techniques; principles and applications, Advanced Techniques and Applications on Scanning Probe Microscopy, 2008, 197-247.

[3] Pradere C., Joanicot M., Batsale J.C., Toutain J. Gourdon C., Processing of temperature field in chemical microreactors with infrared thermogrephy. QUIRT journal, 3, 2006 117-135.

[4] Murshed S.M.S., Leong K.C., Yang C., Thermophysical and electrokinetic properties of nanofluids - A critical review, Applied Thermal Engineering 28 (2008) 2109- 2125

[5] Gongora-Rubio M., Bariatto M., Fontes A., Wagner E., Santiago J., LTCC Hybrid Technology Applied to Water Quality Meso Analytical System. Microelectronics technology and devices, SBMICRO 2002

[6] Choi,S.U.S., Zhang, Z.G., Yu,W., Lockwood, F.E., Grulke, E.A.[2001], Anomalous Thermal Conductivity Enhancement in Nano-Tube Suspensions, Appl. Phys. Lett.,Vol.79, pp.2252-2254.

[7] Yu, W.H., France, D.M., Routbort, J.L., Choi, S.U.S., .[2008], Review and comparison of nanofluid thermal conductivity and heat transfer enhancements, Heat Trans Eng. Vol.28, Iss. 17-18,pp.2109-2125. 